\title{
ANATOMICAL PARAMETERS OF RADIAL HEAD: AN AID FOR PROSTHESIS DESIGN
}

\author{
Anjali Shastry *1, Yogitha Ravindranath ${ }^{2}$, Roopa Ravindranath ${ }^{3}$. \\ ${ }^{* 1}$ Tutor, Department of Anatomy, St Johns Medical College, Bangalore, Karnataka, India. \\ ${ }^{2}$ Professor, Department of Anatomy, St Johns Medical College, Bangalore, Karnataka, India. \\ ${ }^{3}$ Professor, Department of Anatomy, St Johns Medical College, Bangalore, Karnataka, India.
}

\section{ABSTRACT}

Introduction: Radial head and neck fractures are one of the commonly encountered traumatic injuries. Commonly proposed management includes radial head prosthesis implant or open reduction and internal fixation depending on type of injury. Radial head measurements are very valuable in reconstruction of radial head. Appropriate anatomy of radial head will help in preventing postoperative stiffness and enable good rehabilitation.

Aims and objectives: To estimate and compare radial head parameters of proximal end of right and left radii. Materials and Methods: Radial head measurements -Height of radial head in medial (MH) and lateral (LH) side, Antero posterior diameter (APD) and transverse diameters (TD) of radial head, Thickness of ventral (TVC), lateral (TLC) and dorsal (TDC) curves and depth of articular facet (D) were measured with the help of digital caliper. Statistical analysis was done using SPSS software. Difference in sides was measured using independent sample $T$ test ( $p$ value $<0.05$ considered significant).

Results: Mean values of Radial head measurements were APD:19.81mm, TD:18.925mm, MH:9.795mm, LH:7.735mm,TVC:5.05,TDC:3.695,TLC:3.64,D:1.735.There was difference in values of TLC between right and left sides.

Conclusion: Mean values of radial head measurements were comparable with previous studies. Side difference should be considered while implanting prosthesis on affected side.

KEY WORDS: Radial head, Radial neck, radial head prosthesis, rehabilitation.

Address for Correspondence: Dr. Anjali Shastry, Tutor, Department of Anatomy, St Johns Medical College, Bangalore, Karnataka, India. E-Mail: anju_shas@yahoo.com

Access this Article online

Quick Response code

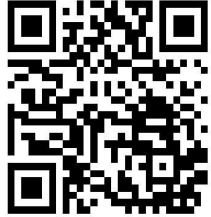

DOI: $10.16965 /$ ijar.2017.476

Journal Information

International Journal of Anatomy and Research

ICV for 2016 ISSN (E) 2321-4287 | ISSN (P) 2321-8967

90.30

https://www.ijmhr.org/ijar.htm

DOI-Prefix: https://dx.doi.org/10.16965/ijar

Article Information

Received: 04 Oct 2017

Peer Review: 05 Oct 2017

Revised: None
Accepted: 01 Dec 2017

Published (O): 05 Jan 2018

Published (P): 05 Jan 2018

\section{INTRODUCTION}

Proximal end of radius consists of radial head, neck and bicipital tuberosity. Radial head and neck fractures represent approximately $1.7 \%$ to $5.4 \%$ of all fractures [1]. Radial head fractures account for approximately one third of all elbow fractures and are involved in approximately $20 \%$ of elbow trauma cases [2]. The treatment of radial head fractures includes immobilization/ early motion, excision with or without prosthetic replacement, and open reduction and internal fixation. Prosthetic replacement of the radial head has been suggested after excision for comminuted fractures. Occasionally, a fracture of the radial head may be a result of a valgus force to the elbow and the injury also may become complicated by a fracture of the olecranon. Some of the currently available radial head implants may significantly alter elbow joint kinematics because of a mismatch 
between their design characteristics and the morphologic characteristics of the proximal radius. Complications that have been reported with current designs include persistent pain, loosening, implant fracture, implant wear, and particulate synovitis. Few clinicians have suggested that a difference of no more than 2 $\mathrm{mm}$ from the patient's native anatomy is tolerated. The size and shape of this proximal extremity are two essential factors to know to enable a biomechanically correct prosthesis to be constructed.

The size and shape of this proximal extremity are two essential factors to know to enable a biomechanically correct prosthesis to be constructed. Further radial head measurements are not described till date in Indian Population.

\section{Aims and objectives:}

1) To estimate the following

(i) Radial head dimensions:

a) Height of radial head in medial $(\mathrm{MH})$ and lateral (LH) side.

b) Anteroposterior diameter (APD) and transverse diameters (TD) of radial head.

c) Thickness of ventral (TVC), lateral (TLC) and dorsal (TDC) curves.

d) Depth of articular facet (D).

2) To estimate the differences in parameters between right and left radii.

\section{MATERIALS AND METHODS}

142 adult dry cadaveric radii (71 right and 71 left) were randomly selected from the department of Anatomy, St John's Medical College, Bangalore. Radii with broken proximal end and ones showing obvious pathology like healed fractures were excluded from the study.

Sample size was calculated using N Master software with mean and standard deviation from previous literature.

Anteroposterior (APD) and transverse diameter (TD) of radial head: Anteroposterior diameter is defined as the distance from the most anterior point on the radial head to the most posterior point. Transverse diameter is defined as the distance from the most medial point on the radial head to the most lateral point measured using digital calipers.
The medial ( $\mathrm{MH}$ ) and lateral (LH) height of radial head: The medial and lateral height of radial head is defined as the distance between the radial lip and the head-neck border measured using digital calipers.

Thickness of ventral (TVC), lateral (TLC) and dorsal (TDC) curves: Thickness of ventral (TVC), lateral (TLC) and dorsal (TDC) curves measured in ventral, lateral and dorsal parts of radial head on articular surface using digital calipers.

Depth (D) of articular facet: A scale placed over the radial head touching the most prominent anterior and posterior rim and the depth in the centre of radial head is measured using digital caliper.

Fig. 1: Measurement of Anteroposterior (APD) and transverse diameter (TD) of radial head.

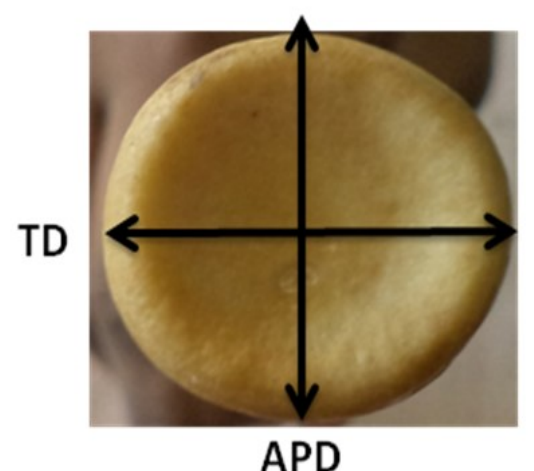

Fig. 2: Measurement of the medial (MH) and lateral (LH) height of radial head.

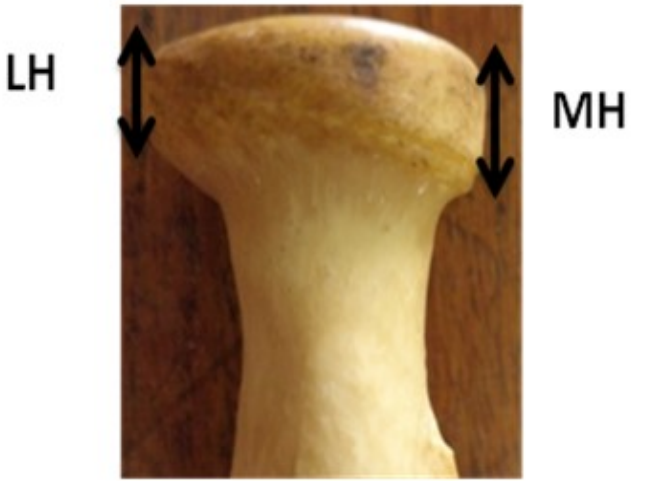

Fig. 3: Measurement of the Thickness of ventral (TVC), lateral (TLC) and dorsal (TDC) curves.

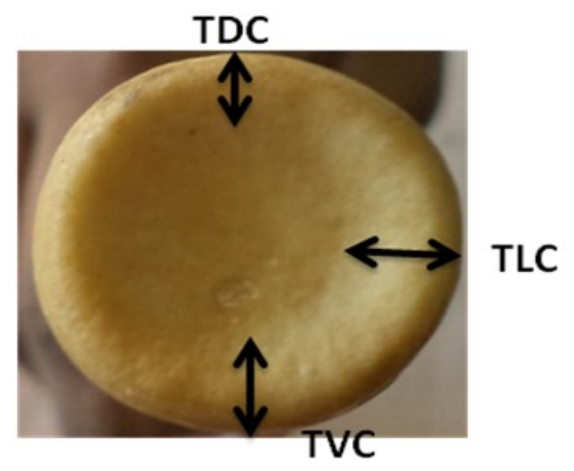




\section{RESULTS AND DISCUSSION}

Table 1: Mean values of the radial head parameters of right and left radii.

${ }^{*} p$ value is significant

\begin{tabular}{|c|l|c|c|c|c|}
\hline S.no & \multicolumn{1}{|c|}{ Parameter } & $\begin{array}{c}\text { Mean } \\
\text { (Left) }\end{array}$ & $\begin{array}{c}\text { Mean } \\
\text { (Right) }\end{array}$ & Mean & P value \\
\hline $\mathbf{1}$ & Antero posterior diameter $(\mathrm{mm})$ & 19.81 & 19.82 & 19.81 & 0.982 \\
\hline $\mathbf{2}$ & Transverse diameter $(\mathrm{mm})$ & 18.81 & 19.04 & 18.925 & 0.512 \\
\hline $\mathbf{3}$ & Medial height $(\mathrm{mm})$ & 9.71 & 9.88 & 9.795 & 0.493 \\
\hline $\mathbf{4}$ & Lateral height $(\mathrm{mm})$ & 7.731 & 7.74 & 7.735 & 0.964 \\
\hline $\mathbf{5}$ & Thickness of ventral curve $(\mathrm{mm})$ & 4.91 & 5.2 & 5.05 & 0.06 \\
\hline $\mathbf{6}$ & Thickness of dorsal curve $(\mathrm{mm})$ & 3.81 & 3.58 & 3.695 & $\mathbf{0 . 0 1 5 *}$ \\
\hline $\mathbf{7}$ & Thickness of lateral curve $(\mathrm{mm})$ & 3.781 & 3.51 & 3.64 & 0.178 \\
\hline $\mathbf{8}$ & Depth of radial head $(\mathrm{mm})$ & 1.721 & 1.75 & 1.735 & 0.617 \\
\hline
\end{tabular}

Radial head dimensions are of great value in reconstruction of radial head. Many authors have described antero lateral and transverse diameters of radial head. King et al, measured the ventro dorsal and transverse diameters of the radial circumference in 28 cadavers and 40 radiographs of the elbow [3].Their measurements did not show any diûerence between the ventrodorsal diameter $(23.4 \mathrm{~mm})$ and the transverse diameter $(23.6 \mathrm{~mm})$ of the anatomical specimens, while on radiographs the transverse diameter was greater than the anteroposterior diameter ( $24.3 \mathrm{~mm}$ and $23.0 \mathrm{~mm}$ respectively). The dimensions of the radial head as measured in the cadaveric specimens were similar to those quantiûed from the radiographs of patients who had undergone a radial head arthroplasty. According to Itamura et al, who did Computed tomography scans of 22 cadaveric adult elbows in 3 forearm positions: full supination, neutral, and full pronation, the ventro dorsal and transverse diameters of the radial head did not change with forearm rotation [4].

Captier et al measured 96 radial bones using a vernier caliper; mean anteroposterior diameter was $21.6 \mathrm{~mm}$ and mean transverse diameter was $21 \mathrm{~mm}$ [5].

Height of radial head is described by few authors. Mean radial head length $(12 \mathrm{~mm})$ in the study by Beredjiklian et al, was similar to the mean dorsal, ventral, radial, and ulnar length of $(11.19 \mathrm{~mm})$ done by Puchwein et al $[6,7]$. Koslowsky has published both radial $(10.02 \mathrm{~mm})$ and ulnar $(11.04 \mathrm{~mm})$ height of radial head [8]. Due to the radioulnar joint surface, they saw a significant difference in the radial head's height on its larger ulnar side compared to the radial non-articulating side. The height of radial head is very important from the biomechanical point of view, and must be conserved to avoid articular complications in both elbow and wrist. When this height decreases due to crushing, fracture or a resection, it results in an upward displacement of the radius and a concomitant distal radioulnar joint dislocation named Essex-Lopresty syndrome.

Captier et al measured thickness of dorsal, ventral and lateral curves of surface of radial head. The thickness of the curve was greater at the ventral edge $(5.5 \mathrm{~mm})$ than at the dorsal $(4.3$ $\mathrm{mm}$ ) and lateral $(4.7 \mathrm{~mm})$ edges [5]. They concluded that this produced a crescent shape whose belly corresponded to the ventral curve. None of the previous studies have measured depth of radial head on dry bone. They mainly measured depth with the of computer tomography $[4,9,10]$. Depth of radial head in the present study $(1.74 \mathrm{~mm})$ was within range of previous studies $(1.5-2.4 \mathrm{~mm})$. This implies that values of depth of radial head taken by CT can be used to design prosthetic head which might help in preventing contact stress and eccentric loading. Diameter, height, depth of radial head describes articulating surfaces for prosthesis design. These parameters will help in better articulation of prosthetic head with capitulum during hemiarthroplasty. Most of previous studies had values similar to present study which showed that there was no much difference between values of radial head parameters when ethnicity is concerned. This implies that stem design of modular prosthesis can be similar in different population.

In present study measurements of radial head is taken in view of preventing postoperative complications following prosthesis replacement. 
Further radiological correlation with dry bone study will give a better picture of anatomy of radial head.

\section{CONCLUSION}

Mean values of radial head measurements were comparable with previous studies. Side difference should be considered while implanting prosthesis on affected side.

\section{ACKNOWLEDGEMENTS}

We thank teaching and non teaching staffs of Department of Anatomy, St John's Medical College.

\section{Conflicts of Interests: None}

\section{REFERENCES}

[1]. Morrey BF. Radial head fracture .The elbow and its disorders. 2nd ed. Philadelphia: WB Saunders, 1993:383-404.

[2]. Mason ML. Some observations on fractures of the head of the radius with a review of one hundred cases. Br J Surg. 1954;42:123-132

[3]. King GJ, Zarzour ZD, Patterson SD, Johnson JA..An anthropometric study of the radial head: implications in the design of a prosthesis. J Arthroplasty. 2001 Jan; 16(1):112-6.

[4]. Itamura JM, Roidis NT, Chong AK, Vaishnav S, Papadakis SA, Zalavras C. Computed tomography study of radial head morphology. J Shoulder Elbow Surg. 2008; 17(2):347-354.
[5]. Captier G, Canovas F, Mercier N, Thomas E, Bonnel F. Biometry of the radial head: biomechanical implications in pronation and supination. Surg Radiol Anat. 2002 Dec; 24(5):295-301.

[6]. Puchwein P, Heidari N, Dorr K, Struger L, Pichler W. Computer-aided analysis of radial head morphometry. Orthopedics. 2013 Jan; 36(1):e51-7.

[7]. Beredjiklian PK, Nalbantoglu U, Potter HG, Hotchkiss RN. Prosthetic radial head com- ponents and proximal radial morphology: A mismatch. J Shoulder Elbow Surg. 1999; 8(5):471-475.

[8]. Koslowsky TC, Germund I, Beyer F, Mader K, Krieglstein CF, Koebke J. Morphometric parameters of the radial head: an anatomical study. Surg Radiol Anat. 2007 Apr; 29(3):225-30.

[9]. Mahaisavariya B, Saekee B, Sitthiseripratip K, Oris $\mathrm{P}$, Tongdee T, Bohez EL, et al. Morphology of the radial head: a reverse engineering based evaluation using three-dimensional anatomical data of radial bone. Proc Inst Mech Eng H. 2004; 218(1):7984.

[10]. Swieszkowski W, Skalski K, Pomianowski S, Kedzior $K$. The anatomic features of the radial head and their implication for prosthesis design. Clin Biomech (Bristol, Avon). 2001;16(10):880-887.

How to cite this article:

Anjali Shastry, Yogitha Ravindranath, Roopa Ravindranath. ANATOMICAL PARAMETERS OF RADIAL HEAD: AN AID FOR PROSTHESIS DESIGN. Int J Anat Res 2018;6(1.1):4827-4830. DOI: 10.16965/ijar.2017.476 